\title{
Immunodiagnosis of Trypanosoma cruzi (Chagas' Disease) Infection in Naturally Infected Dogs
}

\author{
MA Lauricella/ ${ }^{+}$, MB Castañera*, RE Gürtler*, EL Segura** \\ Instituto Nacional de Parasitología "Dr. Mario Fatala Chabén”, Avenida Paseo Colón 568, 1063 Buenos Aires, \\ Argentina *Departamento de Ciencias Biológicas, Facultad de Ciencias Exactas y Naturales, Universidad de \\ Buenos Aires, Ciudad Universitaria, 1428 Buenos Aires, Argentina **Administración Nacional de Laboratorios \\ e Institutos de Salud "Dr. Carlos G. Malbrán”, Av. Vélez Sarsfield 563, 1281 Buenos Aires, Argentina
}

This study reports on the standardization of an enzyme-linked immunosorbent assay (ELISA) for detecting specific antibodies anti-Trypanosoma cruzi in naturally infected dogs. Sera from 182 mongrel dogs of all ages residing in four rural villages in Santiago del Estero, Argentina, were collected in November 1994 and preserved in buffered neutral glycerin. All sera were tested by indirect hemagglutination test (IHAT), indirect immunofluorescence test (IFAT), and ELISA using the flagellar fraction of T. cruzi as antigen. Dog sera from an area without vectorial transmission were used to calculate ELISA specificity and cut-off value. Eighty-six percent of sera had concordant results for all tests. All sera reactive for IHAT and IFAT were also reactive for ELISA, except in one case. Sera tested by ELISA when diluted 1:200 allowed a clearer division between non-reactive and reactive sera than when 1:100 with greater agreement among serologic techniques. The specificity of ELISA was 96.2\%. Among 34 adult dogs with a positive xenodiagnosis, sensitivity was $94 \%$ both for ELISA and IFAT. ELISA is the first choice for screening purposes and one of the pair of techniques recommended for diagnostic studies in dog populations.

Key words: Trypanosoma cruzi - serology - chronic infection - dogs - surveillance

Serological tests used to detect specific antibodies anti-Trypanosoma cruzi in humans allow to confirm a chagasic infection when two or more serological assays are positive (Cerisola 1969). Methodological standardization to achieve this aim has been emphasized in a collaborative work among reference laboratories from Argentina, Brazil and United States (Camargo et al. 1986). Serologic assays are required for the diagnosis of patients, identify uninfected blood donors, in serologic surveillance after application of insecticides (Chuit et al. 1989), and to determine population serologic profiles (Segura et al. 1985). Parameters to evaluate the goodness of a serologic method include sensitivity, specificity, predictive values, the standardization of methods and reagents, and reproducibility, simplicity and cost of the assay (Cura et al. 1992).

\footnotetext{
This study was supported by grants from the Rockefeller Foundation, New York, to Rockefeller University, New York, for a collaborative research project on modeling transmission dynamics and control of Chagas disease in Argentina (Roberto Chuit, Joel E Cohen and Ricardo Gürtler, principal investigators), and from the University of Buenos Aires.

${ }^{+}$Corresponding author. Fax: +54-1-331.7142

Received 11 July 1997

Accepted 4 March 1998
}

Many mammal species constitute important reservoirs of $T$. cruzi, especially dogs (Minter 1976). Dogs are a frequent source of blood meals for domestic triatomines (Gürtler et al. 1997), and in the Argentine chaco, a risk factor in the domestic transmission of the parasite (Gürtler et al. 1991), and a natural sentinel of $T$. cruzi transmission (Castañera et al. 1995). Therefore, a reliable test to identify infected dogs, that can be semi-automated for high capacity testing of blood samples, may be of help in serologic surveillance. For them, serologic techniques employed in patients must be adapted and standardized. Unfortunately, serological reactions applied to human sera are usually employed in domestic and laboratory animals without verifying the validity of test results. Determination of the appropriate cut-off titer for enzymelinked immunosorbent assay (ELISA), as applied to dog sera, is currently lacking. In other studies (e.g. García Vázquez et al. 1995), serodiagnosis for $T$. cruzi infection in dogs was made using ELISA as the only serologic test. Regarding serum dilutions for ELISA, Barr et al. (1991) chose $1 / 64$ for dogs, while others employed $1 / 100$ for dogs, 1/40 for mice and 1/10 for monkeys (Mirta Moreno personal communication).

In a previous study (Lauricella et al. 1993), sera from 482 mongrel dogs were used to estimate sensitivity, specificity and the minimal diagnostic 
titer for complement fixation, direct agglutination, indirect hemagglutination (IHAT), and indirect immunofluorescence (IFAT) tests. The purpose of the present study was to standardize an ELISA for detecting anti-T. cruzi antibodies in dogs residing in an endemic area for Chagas' disease in northwest Argentina. We also report on the correlation between serological and parasitological results and between ELISA and IFAT or IHAT.

\section{MATERIALS AND METHODS}

Study area - The survey was carried out in four rural villages: Amamá, Mercedes, Trinidad and Villa Matilde, Departamento Moreno, Province of Santiago del Estero, Argentina. The villages were situated within $9 \mathrm{~km}$ of each other in semiarid, hardwood thorny forest habitat at $27^{\circ} 12^{\prime} \mathrm{S}$, $63^{\circ} 02^{\prime} \mathrm{W}, 140 \mathrm{~km}$ distant from the capital city. It is a highly endemic area for $T$. cruzi; the prevalence of seropositivity for $T$. cruzi reached $34 \%$ in humans and 65\% in dogs from Amamá in 1992 (Gürtler et al. 1996). In October 1992, Amamá and the other villages were sprayed with deltamethrin (Cecere et al. 1996).

Sera collection - All 96 houses were visited and $182(77 \%)$ of 237 mongrel dogs of all ages were bled by venipuncture in November 1994. Fifty five dogs were not bled by one of the following reasons: owners did not permit bleeding (12); absence of dogs during two visits to the house (16); dog behavior dangerous for handlers or animals that escaped to the forest (15), and unhealthy animals or insufficient blood samples (12). A rapid assessment of each individual's clinical state was carried out.

At the field site, samples were allowed to clot, kept at $4^{\circ} \mathrm{C}$ overnight and serum separated into two aliquots; one was diluted 1:1 in buffered neutral glycerin and stored at room temperature until testing and the other was frozen for future evaluations. Addition of glycerin allows preservation of anti-T. cruzi antibodies in human sera for long periods (Pérez et al. 1989); its usefulness for dog sera has already been demonstrated (Lauricella 1991).

Serology - All serological tests were carried out at the Instituto Nacional de Parasitología "Dr. Mario Fatala Chabén" in Buenos Aires without regard to the identity or previous test result of each individual dog. IFAT was carried out as described by Alvarez et al. (1968). A formaldehyde solution containing T. cruzi epimastigotes (Tulahuén strain) was used as antigen. A phosphate buffer (PB) $\mathrm{pH}$ 7.2 was used to dilute the antigen until reaching 15-20 parasites per microscopic field at $400 \mathrm{X}$. We used a sheep anti-dog IgG (H\&L chains) conjugated with fluorescein isotiocyanate (The Binding Site Limited, Birmingham, England) diluted 1:500 in PB with 1:22.000-Evans' Blue. Dog sera dou- bling dilutions from 1:16 to 1:64 in $\mathrm{PB}$, were placed on the slides, incubated at $37^{\circ} \mathrm{C}$ during $30 \mathrm{~min}$, and rinsed three times with PB. Slides were then incubated with the conjugate for $30 \mathrm{~min}$ at $37^{\circ} \mathrm{C}$, rinsed three times with $\mathrm{PB}$, covered with buffered neutral glycerin and cover glasses, and microscopically examined for fluorescence. Reactive sera from xenodiagnosis-positive dogs having high or low antibody titers for $T$. cruzi and one non-reactive dog serum from an area without vectorial transmission of T. cruzi (Buenos Aires City) were used as controls. For IHAT, a commercially available kit was used (Polychaco S.A.I.C, Buenos Aires, Argentina), and sera titrated in double dilutions to 1:128. Minimal IFAT and IHAT diagnostic titers of seropositivity for $T$. cruzi were 1:16 for both assays (Lauricella et al. 1993).

ELISA was carried out in 96-well microtiter polystyrene plates coated with an homogenate of the flagellar fraction of T. cruzi (Segura et al. 1977). To determine the optimal concentration, the antigen was diluted from 4 to $100 \mathrm{mg} / \mathrm{ml}$ in phosphate buffer saline (PBS) $\mathrm{pH}$ 7.2. The plateau was observed at $20 \mathrm{mg} / \mathrm{ml}$; this concentration was used thereafter. Fifty ml of antigen were added to each well and left overnight at $4^{\circ} \mathrm{C}$. The plates were washed three times with $120 \mathrm{ml} /$ well of PBS containing $0.01 \%$ Tween 20 (PBS/Tween); vacant plastic sites were blocked with $100 \mathrm{mg} /$ well PBS-3\% skimmed milk (Molico, Nestlé) for $1 \mathrm{hr}$ at $37^{\circ} \mathrm{C}$ and washed with PBS/Tween as before.

Each serum sample was diluted to 1:100 (E100) and 1:200 (E200) in PBS-1\% skimmed milk and tested in duplicate. Fifty ml of each serum sample were added to each well and incubated for $1 \mathrm{hr}$ at $37^{\circ} \mathrm{C}$. The plates were washed three times with $\mathrm{PBS} /$ Tween and then incubated with $50 \mathrm{ml} /$ well peroxidase-conjugated rabbit anti-dog IgG (H\&L chains; Biosys, France) diluted to 1:1,200 in PBS$1 \%$ skimmed milk for $1 \mathrm{hr}$ at $37^{\circ} \mathrm{C}$. Seven dilutions of peroxidase-conjugated anti-dog IgG, ranging from 1:300 to 1:3,300, were done to determine the best titer under our laboratory conditions; from these, the 1:1,200 dilution was selected and used thereafter. After washing three times with PBS/ Tween, $50 \mathrm{ml}$ of a substrate solution of $0.04 \% \mathrm{o}$ phenylenediamine-dihydrochloride (Sigma Chemical Co., Saint Louis, Mis., USA) in $0.01 \%$ (v/v) $\mathrm{H}_{2} \mathrm{O}_{2}$ in citrate buffer ( $\mathrm{pH}$ 5.0) were added to each well. Plates were maintained in the dark at room temperature.

When the substrate dilutions started to show a yellowish color, usually within $8-15 \mathrm{~min}$, the reaction was stopped by adding $50 \mathrm{ml} /$ well of $2.5 \mathrm{~N} \mathrm{ClH}$. No difference was found when $1 \mathrm{~N} \mathrm{H}_{2} \mathrm{SO}_{4}$ was used. Within 5-15 min after adding $\mathrm{ClH}$, the absorbance was analyzed on a digital spectrophotom- 
eter reader MR700 (Dynatech Lab. Inc., Buenos Aires, Argentina) at $490 \mathrm{~nm}$. The mean absorbance of each pair of duplicate sera was calculated; if the difference between both values was more than $30 \%$, the sample was retested. Five dog sera reactive for $T$. cruzi from xenodiagnosis-positive animals and five non-reactive dog sera from Buenos Aires, all with concordant IFAT and IHAT results, were used as controls. Each plate had two positive and one negative control sera.

To calculate the specificity of ELISA and the cut-off value, sera from 53 dogs from Buenos Aires were tested by IFAT, IHAT and ELISA as before. Sera were provided by the Instituto de Zoonosis "Dr Luis Pasteur" and came from owned pure-bred and mongrel dogs of all ages. The cut-off value was estimated in two ways: (1) the mean absorbance plus three times the standard deviation (SD) of the results obtained with negative dog sera from Buenos Aires; and (2) the absorbance of the negative control mean $(n=5)$ plus 0.13 times the positive control mean $(n=5)$ (Pan et al. 1992). In addition, we estimated the absorbance that gave a sharper division between non-reactive and reactive sera in the study dog population (i.e., giving the lowest number of discordant samples among serologic techniques). Twenty dog sera from Buenos Aires and 20 xenodiagnosis-positive reactive dog sera were tested by ELISA three times to evaluate reproducibility.

Xenodiagnosis - Thirty-four dogs that had a positive xenodiagnosis for T. cruzi in late 1992 (Gürtler et al. 1996) were used to determine ELISA sensitivity. Each dog had been identified by its name, age, sex and number of family house. In those xenodiagnoses, 20 laboratory-reared uninfected third instar nymphs of Triatoma infestans were fed on each dog during $25 \mathrm{~min}$. Fecal droplets of each individual bug were obtained by abdominal pressure, mixed with physiological saline solution, covered with 22 x $22 \mathrm{~mm}^{2}$ cover glass and microscopically examined for $T$. cruzi infection at $400 \mathrm{X}$ approximately 30 and 60 days after feeding.

\section{RESULTS}

Using 53 dog sera from Buenos Aires, the mean absorbance of ELISA E200 was 0.03 ( $\mathrm{SD}=0.05$ ). Thus, the cut-off value calculated as mean plus 3 $\mathrm{SD}$ was 0.18 . No statistically significant differences between E100 and E200 mean absorbances were observed. Using the second procedure to calculate the cut-off, the mean absorbance of negative control sera was 0.08 ; the mean absorbance of positive control sera was 0.70 . Thus, the cut-off value was 0.17. All 53 dog sera from Buenos Aires were non-reactive for IFAT and IHAT, but two of them had borderline absorbances of 0.18 by ELISA
E200. Therefore, the specificity of IFAT and IHAT was $100 \%$ while that of ELISA E200 was $96.2 \%$.

Fig. 1 shows the frequency distribution of absorbances for ELISA E100 and E200. More diluted sera $(1: 200)$ allowed a clearer division between reactive and non-reactive sera; no serum fell within the absorbance interval 0.14-0.23. Using E100, eight of nine sera with an absorbance in the range $0.14-0.23$ (i.e., within $20 \%$ of the calculated cut-off values 0.17 and 0.18 ) were non-reactive by IFAT and IHAT. Using E100, an absorbance value of 0.20 provided the lowest number of discordant results among techniques.

Of the 182 sera tested, $57(31 \%)$ and $74(41 \%)$ sera were reactive for $T$. cruzi by IHAT and IFAT, respectively (Table I). Seventy-eight (43\%) sera were reactive for E100 (data not shown) and 73 (40\%) were reactive for E200. Seven sera showed discordant results between E100 and E200; five sera reactive for E100 were negative for E200 and the other techniques. Two sera had positive or negative concordant results among E100, IFAT and IHAT. Therefore, we selected E200 as the best serum dilution and used it in the following analyses.

Comparison among ELISA E200, IFAT and IHAT shows that $156(86 \%)$ sera had concordant results among the three techniques (Table I). Of the remaining 26 sera with discordant results, 14 were negative only for IHAT, four were positive only for ELISA and five were positive only for IFAT; the other three sera showed various combinations of results. Though 54 sera were reactive for the three techniques, 70 sera were reactive by at least two techniques. All sera reactive for IHAT and IFAT were also reactive for ELISA E200, except in one case.

\section{TABLE I}

Comparative results among ELISA (E200), indirect immunofluorescence (IFAT) and indirect

hemagglutination (IHAT) tests against Trypanosoma cruzi in 182 dogs; Amamá and close villages, November 1994

\begin{tabular}{llrrr}
\hline \multirow{2}{*}{ ELISA } & & \multicolumn{2}{c}{ IFAT } & \\
\cline { 3 - 4 } Positive & IHAT & Positive & Negative & Total \\
\cline { 3 - 4 } & Negative & $54^{a}$ & 1 & 55 \\
& Total & 68 & 4 & 18 \\
Negative & Positive & 1 & 1 & $73^{c}$ \\
& Negative & 5 & $102^{b}$ & 107 \\
& Total & 6 & 103 & 109 \\
\hline Total & & & 108 & 182 \\
\hline
\end{tabular}

$a$ : positive for three techniques; $b$ : negative for three techniques; $c$ : ELISA reactive sera. 


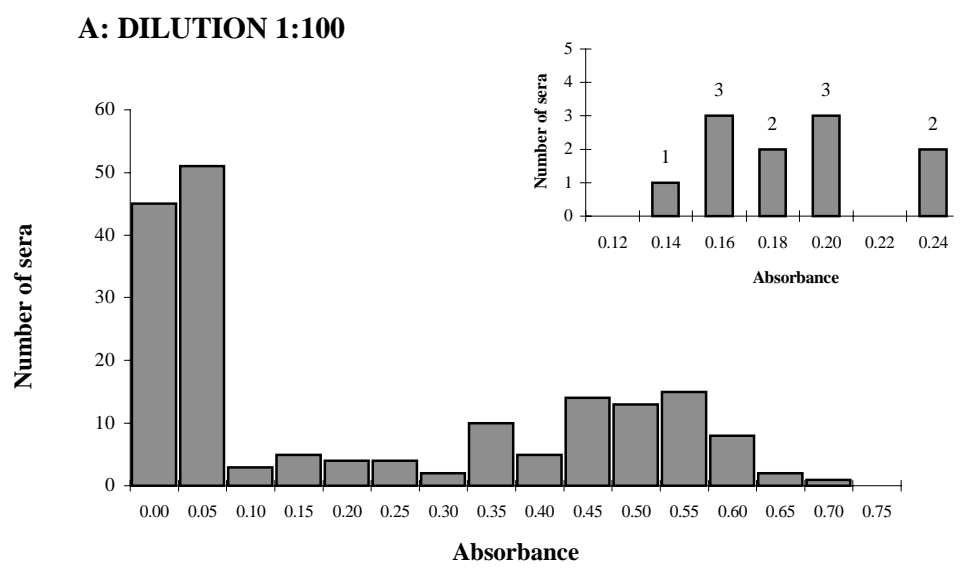

\section{B: DILUTION 1:200}

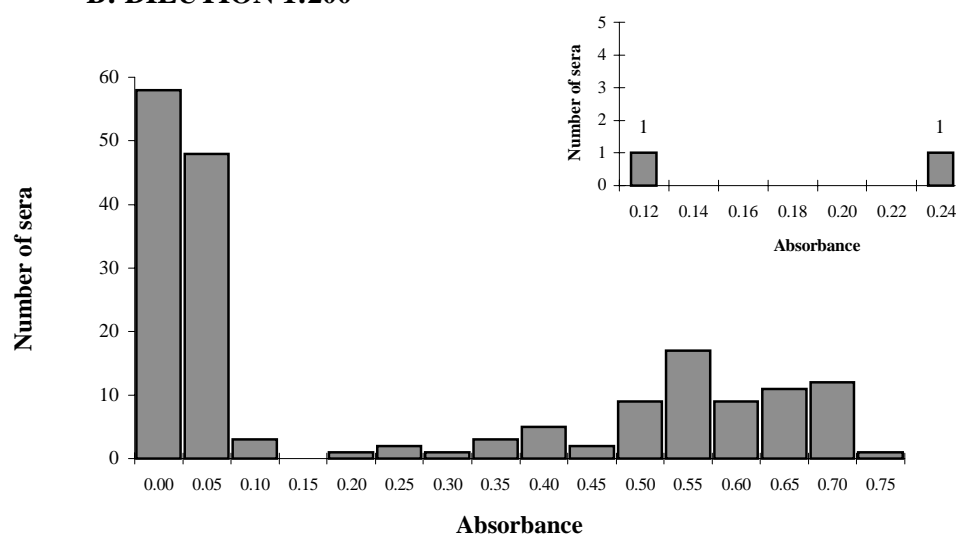

Fig. 1: frequency distribution of ELISA absorbance (lower class limits shown) for 182 dog sera from Amamá and neighboring villages, November 1994. A: 1:100 serum dilutions (E100); B: 1:200 serum dilutions (E200). Embedded figures show the distribution of sera close to the cut-off values; numbers on each bar are numbers of sera.

Fig. 2 shows the joint frequency distribution of titers for ELISA E200 and IFAT. Among 12 sera with discordant results, the test that was reactive showed significant (not borderline) titers. Using IFAT as the reference for ELISA E200, co-positivity was $0.92(67 / 73)$ and co-negativity was 0.94 (103/109).

All sera from the 34 dogs with a positive xenodiagnosis showed seroreactivity for $T$. cruzi by ELISA E200 except in two cases (Table II); one of them was also not reactive for IFAT and IHAT. Twenty-two sera were reactive for the three assays. Sensitivity estimates were calculated as the proportion of the xenodiagnosis-positive dogs tested that were reactive for a given technique. The sensitivity of ELISA and IFAT was 94\% (32/34), whereas IHAT sensitivity was $68 \%(23 / 34)$.

Fig. 3 shows the mean $( \pm$ SD) absorbance of 20 dog sera from Buenos Aires and 20 xenodiagnosis-positive reactive dog sera tested by ELISA E200

\section{TABLE II}

Concordance among ELISA (E200), indirect immunofluorescence (IFAT) and indirect hemagglutination (IHAT) tests in sera from 34 dogs with a positive xenodiagnosis; Amamá and close villages, November 1994

\begin{tabular}{llrrr}
\hline \multirow{2}{*}{ ELISA } & & \multicolumn{2}{c}{ IFAT } & \\
\cline { 3 - 4 } Positive & IHAT & Positive & Negative & Total \\
& Negative & $22^{a}$ & 1 & $23^{b}$ \\
& Total & 9 & 0 & 9 \\
\hline \multirow{2}{*}{ Negative } & Positive & 0 & 1 & $32^{c}$ \\
& Negative & 1 & $1^{e}$ & 0 \\
& Total & 1 & 1 & 2 \\
\hline Total & & $32^{d}$ & 2 & 34
\end{tabular}

$a$ : positive for three techniques; $b$ : IHA sensitivity $=68 \%$ (23/34); $c$ : ELISA sensitivity $=94 \%$ (32/34); $d$ : IFAT sensitivity $=94 \%(32 / 34) ; e$ : negative for three techniques. 


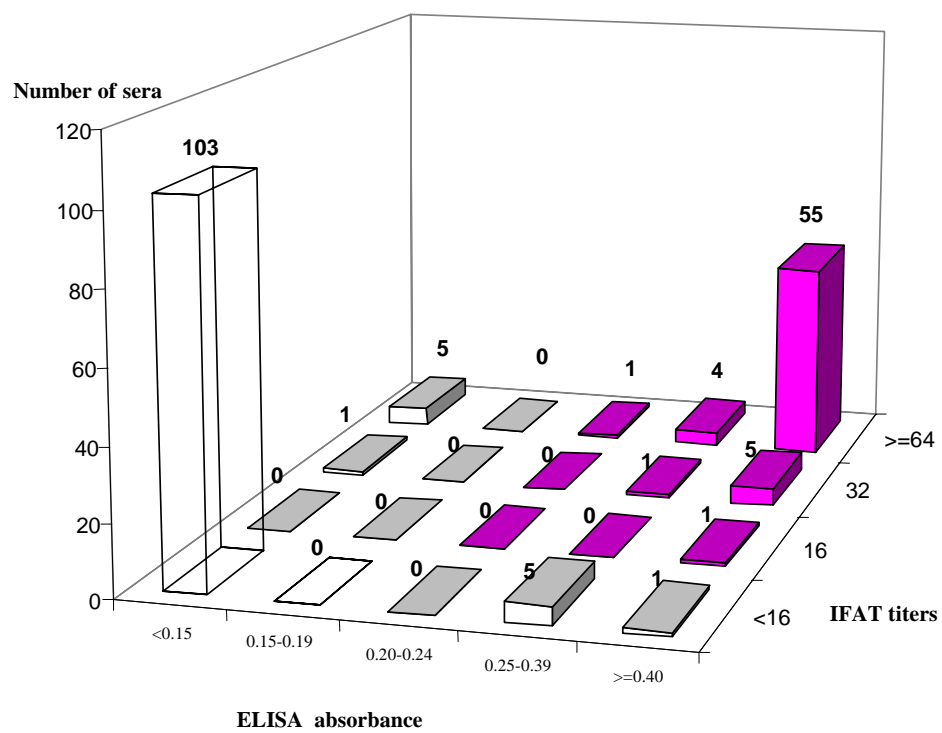

Fig. 2: joint frequency distribution of ELISA (E200) absorbances and titers for indirect immunofluoresce test (IFAT).

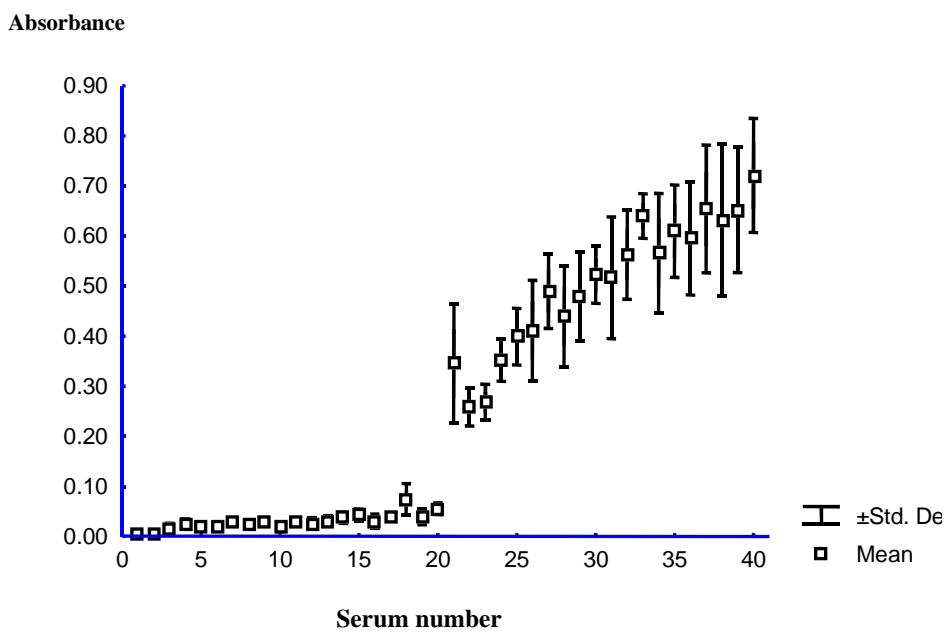

Fig. 3: mean absorbance and standard deviation (SD) for 20 dog sera from an area without vectorial transmission and 20 xenodiagnosis-positive dog sera tested by ELISA (E200) three times.

three times. The overall coefficient of variation of absorbance values was $16 \%$ for xenodiagnosispositive reactive dog sera and $36 \%$ for negative control sera. In spite of increasing variability among readings with increasing absorbance values, no reactive dog sera fell below the cut-off value.

\section{DISCUSSION}

Our study shows that ELISA was as sensitive as IFAT, which in previous studies was shown as the most sensitive technique among those assayed (Lauricella et al. 1993). However, both ELISA and IFAT revealed sera reactive for $T$. cruzi that the other technique failed to detect.

The serum dilution 1:200 (E200) allowed a clearer division between positive and negative sera than 1:100 (see Fig. 1); five of seven ELISA E200negative sera were negatively concordant with the other serological techniques. Considering the weak health status of dog populations from these impoverished rural areas, it is likely that low titers of unspecific antibodies due to other infectious agents were eliminated by using more diluted sera.

The cut-off value for ELISA E200 varied little from 0.17 to 0.18 by two procedures; the frequency distribution of absorbances in Fig. 1 showed no data within $20 \%$ of cut-off values. However, two 
(3.8\%) dogs from Buenos Aires tested positive by ELISA E200 when those cut-off values were used. When E100 was used, an absorbance of 0.20 provided the lowest number of discordant samples among techniques; the interval from 0.14 to 0.23 included eight of nine sera non-reactive for IFAT and IHAT, most of which would have been considered positive with a cut-off of 0.17 or 0.18 . Taking a more conservative approach, a cut-off value of 0.20 for both serum dilutions would provide both a sensitive and specific serodiagnosis for T. cruzi.

Of 34 sera from xenodiagnosis-positive dogs, ELISA E200 missed two samples, one of which tested positive by IFAT. Both dogs had a positive xenodiagnosis 1-2 years before, and one of them also tested positive by ELISA and IHAT. Therefore, both dogs were not in the acute, serologically unresponsive, phase of infection by November 1994. Moreover, one of the ELISA-negative, xenodiagnosis-positive dogs tested positive by ELISA and IFAT in 1996 (unpublished results). Mislabeling of sera or a wrong identification of the animal were unlikely due to tight control procedures. These two dogs might have been either severely undernourished, which is not uncommon in the study area, immunosupressed or both. Regarding malnutrition, mice on a protein-deficient diet dropped their specific T. cruzi immune response (Carlomagno et al. 1996). Human beings infected with T. cruzi or Toxoplasma gondii and subjected to organ transplants were seronegative as a consequence of immunosuppresive treatment (Vázquez et al. 1993, Derouin et al. 1993).

Leishmania sp. and T. cruzi produce serologic cross-reactions that can be differentiated by immunoblotting (Chiaramonte et al. 1996). However, very few human cases of Leishmania sp. were notified in Departamento Moreno (Santiago del Estero) since 1992, and all of them occurred far from our study area (Yadón 1996). In addition, dogs from the study villages did not show apparent signs of Leishmania infection, such as desquamation, alopezia, erythema, ulceration and depigmentation (Opitz 1996). Therefore, the likelihood of "false positive" serologic reactions due to Leishmania sp. in the study dogs seems remote. Using sera from dogs residing in Buenos Aires, we showed ELISA E200 to be $96.2 \%$ specific. However, we did not test sera from dogs showing specific diseases.

Greater uniformity in binding antigens to plates is achieved with less heterogeneous antigen preparations (Venkatesan \& Wakelin 1993). In our study, we used the flagellar fraction of T. cruzi. However, in a preliminary comparison between the flagellar fraction and a total homogenate of T. cruzi as applied to ten positive and ten negative control sera, we obtained comparable results with both antigens using ELISA E200 (unpublished).

The present sensitivity estimate for IFAT agreed with a previous one (Lauricella et al. 1993), in spite of using different commerically available conjugates. For IHAT, however, differences between a previous $(84 \%)$ and the present sensitivity estimate (68\%), separated by almost ten years, are not uncommon when different batches of commercially available kits are used. In any case, our xenodiagnosis-positive set of sera was limited in number. Therefore, sensitivity estimates may be markedly affected by even one or two anomalous cases.

In human immunodiagnosis of Chagas' disease, ELISA has a high level of reactivity (small amount of antigens and antibodies required for diagnosis) while IFAT and IHAT have an intermediate level (Cura et al. 1992). As stated by Hoff et al. (1985), the most important practical advantages of ELISA are that reagents are relatively inexpensive and that the test can be read objectively and quantitatively using an ELISA plate reader. This makes ELISA specially apt for mass testing of serum samples. At present, ELISA is the first choice for screening antiT. cruzi antibodies in dog populations for serologic surveillance after insecticide sprays and apparent elimination of triatomine bugs, and is a recommended technique for individual serodiagnosis.

\section{ACKNOWLEDGMENTS}

To Dr Abel Hurvitz and his staff at the National Chagas Service (Argentina) for providing active support throughout this study, and Adriana Grippo for assistance during fieldwork. To Mrs María Moyano and Mr Omar Sitatti for kindly providing field accommodation. To Dr Ricardo Iachini (Instituto de Zoonosis " $\mathrm{Dr}$ Luis Pasteur", Buenos Aires) for providing dog sera. To Drs Juan Carlos Lansetti, Andrés Ruiz, Mónica Esteva and two anonymous referees for helpful comments.

\section{REFERENCES}

Alvarez M, Cerisola JA, Rohwedder RW 1968. Test de inmunoflorescencia para el diagnóstico de la Enfermedad de Chagas. Bol Chil Parasitol 23: 4-9.

Barr SC, Dennis VA, Klei TR 1991. Serologic and blood culture survey of Trypanosoma cruzi infection in four canine populations of southern Louisiana. Am J Vet Res 52: 570-573.

Camargo ME, Segura EL, Kagan IG, Pacheco Souza JM, Rocha Carvalheiro J da, Yanovsky JF, Guimarães MC 1986. Three years of collaboration on the standardization of Chagas' disease serodiagnosis in the Americas: An appraisal. Bull PAHO 20: 133-144.

Carlomagno M, Leer G, Esteva M, Hansen D, Segura EL 1996. Role of protein deficiency on the course of Trypanosoma cruzi infection and on the degree of protection conferred by a flagellar fraction. $J$ Nutrit Immunol 4: 37-45.

Castañera MB, Lauricella MA, Chuit R, Gürtler RE 1995. El perro como centinela natural de la 
transmisión del Trypanosoma cruzi. Primer Congreso Argentino. Primer Congreso Latinoamericano de Zoonosis, Buenos Aires, Argentina.

Cecere MC, Gürtler RE, Canale D, Chuit R, Cohen JE 1996. El papel del peridomicilio en la eliminación de Triatoma infestans de comunidades rurales argentinas. Bol Of Sanit Panam 121: 1-10.

Cerisola JA 1969. Evolución serológica de pacientes con enfermedad de Chagas aguda tratados con Bay 2502. Bol Chil Parasitol 24: 54

Chiaramonte MG, Zwirner NW, Caropresi SL, Taranto NJ, Malchiodi EL 1996. Trypanosoma cruzi and Leishmania spp. human mixed infection. Am J Trop Med Hyg 54: 271-273.

Chuit R, Subias E, Pérez AC, Paulone I, WisniveskyColli C, Segura EL 1989. Usefulness of serology for the evaluation of Trypanosoma cruzi transmission in endemic areas of Chagas' disease. Rev Soc Bras Med Trop 22: 119-124.

Cura EN, de Titto E, Segura EL 1992. El diagnóstico y su control de calidad en la infección por Trypanosoma cruzi, p. 125-131. In R Madoeri, C Madoeri, MI Cámera (eds), Actualizaciones en la Enfermedad de Chagas. Simposio Satélite Córdoba.

Derouin F, Devergie A, Auber P, Cluckman E, Beauvais B, Garin YJF, Lariviere M 1993. Toxoplasmosis in bone-marrow-transplant recipients: Report of seven cases and review. Clin Inf Dis 15: 267-270.

García Vázquez Z, Rosario-Cruz R, Miranda-Miranda E, Domínguez Márquez A 1995. A serological survey of Trypanosoma cruzi infection in dogs of two urban areas of Mexico. Prev Vet Med 25: 1-6.

Gürtler RE, Cecere MC, Rubel DN, Petersen RM, Schweigmann NJ, Lauricella MA, Bujas MA, Segura EL, Wisnivesky-Colli C 1991. Chagas' disease in north-west Argentina: infected dogs as a risk factor for the domestic transmission of Trypanosoma cruzi. Trans $R$ Soc Trop Med Hyg 85: 741-745.

Gürtler RE, Cecere MC, Castañera MB, Canale D, Lauricella MA, Chuit R, Cohen JE, Segura EL 1996. Probability of infection with Trypanosoma cruzi of the vector Triatoma infestans fed on infected humans and dogs in northwest Argentina. Am J Trop Med Hyg 55: 24-31.

Gürtler RE, Cohen JE, Cecere MC, Chuit R 1997. Shifting host choices of the vector of Chagas disease Triatoma infestans and the availability of hosts in houses in north-west Argentina. J Appl Ecol 34: 699-715.

Hoff R, Todd CW, Maguire JH, Piesman J, Mott KE,
Mota EE, Sleigh A, Sherlock IA, Weller TH 1985. Serologic surveillance of Chagas' Disease. Ann Soc Belge Med Trop 65 (Suppl. 1): 187-196.

Lauricella MA 1991. El Perro como Hospedador del Trypanosoma cruzi: Comparación de los Perfiles de Infección y Enfermedad entre el Modelo Experimental de la Enfermedad de Chagas y los Reservorios Caninos de Áreas Endémicas Argentinas, $\mathrm{PhD}$ Thesis, Universidad de Buenos Aires, Facultad de Ciencias Exactas y Naturales, 205 pp.

Lauricella MA, Wisnivesky-Colli C, Gürtler R, Petersen R, Bujas M, Segura EL 1993. Standardization of serological tests for detecting anti Trypanosoma cruzi antibodies in dogs. Mem Inst Oswaldo Cruz 88: 413417.

Minter DM 1976. Effects on transmission to man of the presence of domestic animals in infested households. In New Approaches in American Trypanosomiasis Research. PAHO Sci Publ 318: 330-337.

Opitz M 1996. Skin manifestations in leishmaniasis in dogs. Tierarztl (Germany) 24: 284-291.

Pan AA, Rosenberg GB, Hurley MK, Schock GJH, Chu VP, Aiyappa A 1992. Clinical evaluation of an EIA for the sensitive and specific detection of serum antibody to Trypanosoma cruzi (Chagas' disease). J Inf Dis 165: 585-588.

Pérez AC, Cura E, Subias E, Lansetti JC, Segura EL 1989. Long-term preservation of blood samples for diagnosis of Trypanosoma cruzi infection. Trop Med Parasitol 41: 75-76.

Segura EL, Vázquez C, Bronzina A, Campos JM, Cerisola JA, González Cappa SM 1977. Antigens of the subcellular fractions of $T$. cruzi. II Flagellar and membrane fraction. J Protozool 23: 540-543.

Segura EL, Pérez AC, Yanovsky JF, Andrade J, Wynne de Martini GJ 1985. Disminución en la prevalencia de infección por T. cruzi (Enfermedad de Chagas) en hombres jóvenes de la Argentina. Bull PAHO 19: 252-264.

Vázquez MC, Zala C, Alvarez F 1993. Evolución de pacientes chagásicos transplantados renales. Nefrología 12 (Suppl. 2): 57-58.

Venkatesan P, Wakelin D 1993. ELISAs for parasitologists: or lies, damned lies and ELISAs. Parasitol Today 6: 228-232.

Yadón ZE 1996. Risk Factors for American Cutaneous Leishmaniasis in Santiago del Estero, Argentina: A Retrospective Case-control Study, $\mathrm{PhD}$ Thesis, Faculty of Medicine, University of London, $225 \mathrm{pp}$. 
